\title{
Interview with James McKerrow
}

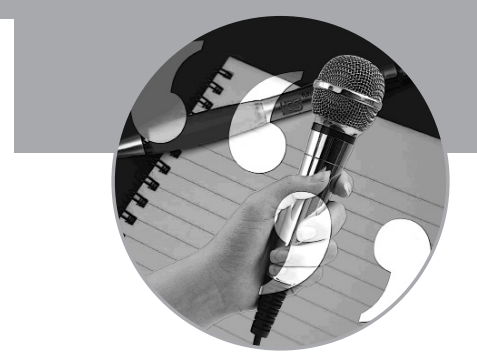

James McKerrow's research interests focus on the biology of the host-parasite relationship, from primitive single-cell protozoa to complex multicellular bloodflukes. His group employs techniques from a variety of disciplines to develop new drugs for parasitic diseases. He speaks to Future Medicinal Chemistry about what inspired him to enter research and offers his take on the state of the neglected diseases R\&D landscape.

Why do neglected diseases interest you?

A lot of it has to do with a feeling of responsibility towards other people in the world. In particular, those who may not have the necessary resources to ensure that they have good health. I would say that my primary motivation derives from my family background - I come from a family where everyone, back to my grandparents, was involved, in one way or another, with helping other people. A century ago it was running part of the underground railroad to help slaves escape to Canada. My father was a social worker, my mother, sister and daughter all teachers. Let's put it this way, no one in my family went into business - a sense of responsibility to help other people is part of our psyche. As a scientist the second thing that drew me to neglected tropical diseases, particularly the parasites causing these diseases, is in fact that I found the biology really fascinating, particularly the evolution and adaptation that characterizes host-parasite interactions. In addition, my own education was very eclectic, covering both basic science and medical training, so neglected diseases was an area where these two seemingly disparate parts of my education could converge.

After obtaining your PhD in biology, you then went on to medical school. How has having a medical background influenced your subsequent research?

I think it had a very profound influence because it gave my research a focus on problems that I recognized as being medically relevant. What I did during my $\mathrm{PhD}$ was basic biological chemistry but once I got medical training and, particularly, once I had experience of working with patients, I could appreciate how healthcare works - or does not - in tropical areas of the world. This focused my research away from extremely basic science to areas of medical need.

You later went back to research, completing a Postdoctoral Fellowship on Protease Biochemistry \& Cell Biology at the University of California, San Francisco. What drew you back?

As I tell my students, "never take the career path I took", because it was so convoluted. When I finished my college degree, which was jointly in chemistry and biology, I was first and foremost interested in science, so that's why I did my PhD. When I finished my PhD and made the decision to go to medical school it was with the intention that I would go back into research after medical training. So, when I finished medical school I intended immediately to do a postdoctoral fellowship, but by that time my advisor in medical school was a clinician who, when I said, "I'm finishing my medical training and going back to the laboratory", replied, "Oh no you're not! Society has just invested all of this money in your medical education and now you have to pay it back by treating people!" So I ended up doing a year of an internship in internal medicine and then approximately 6 months working in a family practice clinic on Long Island. I then completed an additional 3 years of training in pathology. By that time I felt I had, well everyone felt I had, paid my debt back to society. I finally started a post-doctoral fellowship, which was necessary, since by that point it had been many years since I had been in a laboratory and much had happened in the interim, notably the explosion of molecular biology. The initial aim of my post-doctoral fellowship was to bring me up to speed with new technology and then focus my attention on the future area of my research.

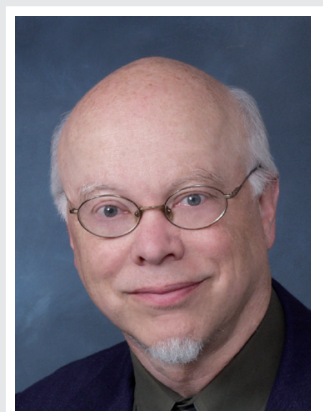

\section{James McKerrow}

Sandler Center for Drug Discovery, Department of Pharmaceutical Chemistry, University of California, 17004 th Street, Suite 214,

San Francisco, CA 94158, USA

E-mail: jmck@cgl.ucsf.edu

\section{FUTURE SCIENCE}




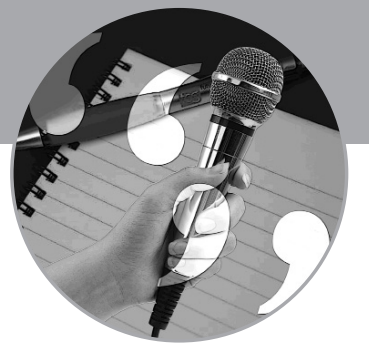

Q Please can you update us on some of the research activities in which your group is currently engaged in relation to neglected diseases?

There are two parallel tracks: the first reflects my interest in the biology of host-parasite relationships. We are interested in issues such as: how do multicellular parasites, such as the schistosome worm, manage to get into the human host? Once these organisms get into the bloodstream, whether they are schistosomes, trypanosomes or Leishmania, how do they manage to evade the host immune response, particularly organisms that are fairly large. Finally, how do these organisms manage to acquire the nutrients necessary to carry on their own metabolism and growth? In studying these issues over the past decade or so, we have identified aspects of the metabolism of a number of different organisms that suggested avenues of therapeutic intervention. Our research is coupled with a recognition gained from my own travels and clinical experience, that these are organisms and diseases that cause huge global health problems. While they affect hundreds of millions of people, there is little or no interest from traditional commercial entities in developing new drugs. So, if new drugs are to be developed, they will have to come about from a strategy other than the typical market-driven drug-development process.

Q Since you began your career, how has the attention given to neglected diseases changed?

I think there has been a dramatic change, for a number of different reasons. While these diseases are still 'neglected' in the sense that they still are not a major focus for the pharmaceutical industry, they are receiving more public attention. In part that is a result of people traveling, which opens us to new locations and perspectives. Also, we have the experience of soldiers from developed countries contracting diseases following military excursions in parts of the world where these diseases are endemic. Finally, I think that the globalization of the world's economy has meant that factories have been established in areas of the world where they had not been before, because of cheap labor, and multinational corporations are beginning to realize that their labor force is exposed to, and is acquiring, some of these diseases. Malaria, for instance, is a disease that most people are now aware of. Some of the other neglected diseases still seem very exotic, but certainly a whole lot less exotic than they used to be. Over the past 5-10 years, there has also been the entry of alternative sources of funding from philanthropy. Prior to a decade ago, pharmaceutical companies weren't interested in these diseases and the WHO, which was interested, could do little owing to chronic under-funding. Therefore, it was left to government agencies. There was a recognition that these diseases were important, but support paled in comparison to that for, say, prostate cancer or Alzheimer's disease. The advent of organizations, such as the Gates Foundations, the Sandler Foundation, the Wellcome Trust and so on, which serve as alternative funding sources, has not only increased interest in the field within the scientific community but also has increased opportunities for people to start addressing some of the questions that couldn't be tackled before.

\section{Q Do you think big pharmaceutical companies are doing their fair share to support \&} stimulate R\&D into neglected diseases?

I definitely don't think they are doing their fair share. I've talked to a lot of people in big pharmaceutical companies as well as in biotechnology who will emphasize that their company is a business not a philanthropic organization. Their role is to ensure a profit to shareholders. That is their bottom line and from a strictly business point of view it is hard to argue with them. It's not that they have done nothing for the field of neglected diseases - but I think that whenever something is done they make sure that the media hear about it! You find big pharmaceutical companies entering the field when they see that there is a funding stream where they can get good publicity or where they see they could open an emerging market. But, in the end, R\&D on neglected diseases has to be at least revenue-neutral. Of course, there are many companies that don't get into this at all. I don't want to sound negative about it but I think that the contribution from industry are not as great as often perceived. Compare the development of anti-HIV drugs to the development of drugs for leishmaniasis: if commerical companies were really interested in drugs for leishmaniasis then we would have had them years ago - there just isn't a market. 
Some engaged in neglected disease R\&D have identified intellectual property \& regulatory issues as being major barriers to innovation \& access to treatments. What are your thoughts on this?

There certainly are barriers but I think that whole area is very controversial and when you speak to different people you get a range of viewpoints. For neglected diseases, whatever drug, vaccine or diagnostic tool you put out is not going to be a big blockbuster financially. In fact, you may lose money. That raises the issue of, "Well, if you're not making any money from it then why is intellectual property (IP) so important?" A lot of people have that attitude. On the other hand, there's an argument often put forward that without IP, you'll never interest a big company in producing a product if you manage to deveop a product for one of these diseases. It may be important to have the IP for that reason. Both of those arguments are fairly cogent. However, if we take the idea that IP is important, then yes there are barriers. For example, we screen compound libraries from companies that come to us with what is called a material-transfer agreement. In that agreement it spells out who has rights to what. Very often companies tell us that we can screen a compound library but if we find anything worthwhile then it's up to us to develop it, they will not support us financially. Furthermore, we are restricted to using that compound only for human neglected diseases. Another not uncommon problem is that if you get to a stage where you actually come up with something that is a potential drug and you're about to enter into a clinical trial, then a company that owns the IP might halt development because there is a risk of testing the drug in a larger population to treat a neglected diseases. Specifically, severe but less common side effects may show up so a company may become concerned if a parallel use of this drug is envisioned for a more profitable money-making target.

What are your thoughts on incentives schemes, such as, for instance, the US FDA's priority review voucher award?

I think these are great ideas. One of the things we do is screen drugs against parasitic organisms that have been already approved by the FDA for other therapy. We found one drug that had been marketed since 1985 for rheumatoid arthritis; it's bioavailable and safe, but it happens to kill Entamoeba histolytica, which causes amebiasis. We then applied to the FDA for orphan-drug status and received it, and that's been very useful for us in going to the company that holds the license for this drug and saying, "You let us develop this for amebiasis, we'll get the money for clinical trials, but there are incentives for you."

As regards the voucher program, it is limited to what are known as new chemical entities. In order to get the voucher you have to file an investigational new drug application for a neglecteddisease drug that isn't already approved for something else. But, even in that case, there are other incentives from the FDA, such as an exclusive license that lasts longer than the usual patent. The FDA really understands that there has to be a carrot to get companies to play the game. Another example is what the Gates Foundation, as well as other organizations, have established or proposed as 'global funds'. In these cases, they might tell a company, "If you produce 200,000 or 2 million doses of this drug for, say, African sleeping sickness, then we are guarantee to buy it through this fund."

What role can open-data initiatives play in supporting neglected diseases research? For the types of diseases we are talking about, where funding is limited, making research and data as open-source as possible, is very important. There are several cogent reasons to support open data initiatives. I think one of the most important is minimizing redundancy. This is a field where, even given philanthropy, there is still limited funding, so what you don't want are three laboratories all screening the same compounds and not telling each other! This can happen as there is no open-source database for researchers to keep up to date with what is happening elsewhere. The reason is in part the issue of IP. Say you're screening drugs from a company against neglected tropical diseases. That company is likely to have put some type of propriety wall around those drug structures so that you wouldn't be able to share that information with others. That's a valid issue but, at the same time, you could negotiate a compromise so that you can at least tell the community that, "someone is screening against these specific parasites using a drug library from this specific company". Funding agencies as well as companies may also put up barriers, which has limited people's ability to share this information in an open-source format. 


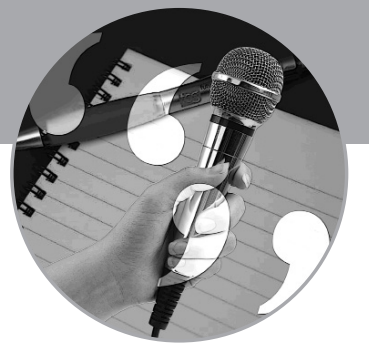

You have been involved in numerous combined research efforts. What are your experiences of coordinating a collaborative research group between disparate research groups \&/or academic and industry-based researchers?

I think that collaborative arrangements are absolutely essential for any progress in this field. Since there are limited resources, one needs to bring together a working partnership. No individual or single organization, university laboratory or company is going to have the money to do this type of research alone. I would say that our most productive collaborations begin with those that are fostered by the kind of environment I am fortunate enough to enjoy at my university; that is, a very interactive culture. Not all universities are like that but in our university we can turn to chemists, to x-ray crystallographers, cell culture specialists, those working on animal models, and they're all willing to work together towards the goal of finding a drug for the treatment of Chagas disease, leishmaniasis or schistosomiasis. They're very motivated by the global health aspect and they're very willing to share their expertise and equipment. So I think it begins with having that spirit. Second, collaborations between noncommercial and commercial entities are also key. For instance, one place where we have found that companies can play and have played a role is in sharing libraries of drug-like compounds for us to screen. The best situations are those in which if you find something you are free to develop it. That depends on the company and the attitude of its employees, however those have been the most productive collaborations. Companies will invariably screen their compound libraries very early on for drug-like properties. And so when you screen these compounds and you find something that kills Trypanosoma brucei, for example, you can be pretty confident that you can take that into an animal model for proof of principle. Even if it needs some chemical tinkering, at least it has already undergone a great deal of preclinical testing so that you're much further down the development route. The reasons why these collaborations sometimes arise are rather interesting. Sometimes the company just wants good publicity; sometimes this is a way they can get funding from business grants or philanthropy. Another reason that I have encountered is someone from the company, often a chemist, will say "Look we'll share this library as long as you don't tell my VP". To which I say "OK but why are you doing this?", and they'll say "I used to work for the US Peace Corps in Africa and I saw the effects of malaria". I think this sort of motivation, based on direct experience, is not uncommon.

What words of encouragement would you give young scientists who might be envisioning a career in neglected diseases research?

I am very positive about it and express that to my own students and postdoctoral fellows. First of all, scientifically this is an incredibly fascinating area of research. The adaptations that these organisms have made to exist within the human or animal host are remarkable and, by and large, remain undiscovered. So there is a tremendous amount of interesting biology, molecular biology, cell biology and biochemistry that has not yet been explored. Second, I encourage students to enter this area since when you are engaged in this field it also feeds your social conscience. You are working on diseases that affect the world's most needy people, and so you have the potential to make a very positive impact. Also, because relatively few people are working in this area, if you do make a discovery you can really make a difference. What is also encouraging to young scientists is that there are new funding streams for this research. It's not aging, it's not lowering cholesterol, it's not cancer, and you're not going to get that funding from just any source but, nevertheless, it's a whole lot better than it was and there are certainly more opportunities for young scientists to be supported for doing this kind of work.

\section{Financial \& competing interests disclosure}

The author has no relevant affiliations or financial involvement with any organization or entity with a financial interest in or financial conflict with the subject matter or materials discussed in the manuscript. This includes employment, consultancies, honoraria, stock ownership or options, expert testimony, grants or patents received or pending, or royalties.

No writing assistance was utilized in the production of this manuscript. 